\title{
EDUCAÇÃO AMBIENTAL PARA O ENSINO DE QUÍMICA: UTILIZAÇÃO DOS OBJETOS VIRTUAIS DE APRENDIZAGEM
}

\author{
Felícia Maria Fernandes Oliveira, Professora da rede estadual de ensino da Paraíba. \\ Edilson Leite da Silva, UFCG
}

\begin{abstract}
RESUMO
No território brasileiro, assim como em outros lugares do mundo é grave a situação socioambiental. Diante disso a Educação Ambiental deve ser implementada na geração atual com o intuito de formar atitudes de emergência frente aos problemas ambientais. Esta pesquisa objetiva demonstrar o uso dos Objetos Virtuais de Aprendizagem (OVA) como ferramenta auxiliadora no processo de ensino aprendizagem com ênfase em Química Ambiental como ferramenta auxiliadora no processo educacional. Trata-se de uma pesquisa bibliográfica, ação e descritiva. Os resultados da pesquisa mostraram que todos os discentes não conheciam o BIOE, a grande maioria não sabia o que é um OVA, bem como afirmaram que o ser humano é o maior responsável pelos problemas ambientais. Além disso, a maioria dos alunos afirmaram que os OVAs utilizados facilitaram a aprendizagem do conteúdo. Os OVAs são um forte aliado ao processo educativo, pois levam a compreensão e permitem o entendimento de determinados conceitos.
\end{abstract}

PALAVRAS-CHAVE: Química; educação; tecnologia.

\section{ENVIRONMENTAL EDUCATION FOR TEACHING CHEMISTRY: USE OF VIRTUAL LEARNING OBJECTS}

\begin{abstract}
In Brazil, as in other parts of the world, the socio-environmental situation is serious. In view of this, Environmental Education must be implemented in the current generation in order to form emergency attitudes towards environmental problems. This research aims to demonstrate the use of Virtual Learning Objects (OVA) as a supporting tool in the process of teaching learning with emphasis in Environmental Chemistry as a supporting tool in the educational process. It is a bibliographical research, action and descriptive. The results of the research showed that all the students did not know the IBEO, the great majority did not know what a VLO is, as well as affirmed that the human being is responsible for the environmental problems. Besides, most students stated that the LVOs used facilitated the learning of content. The LVOs are a strong allied to the educational process, because they lead to understanding and allow the understanding of certain concepts.
\end{abstract}

KEYWORDS: Chemistry; education; technology.

\section{INTRODUÇÃO}

A Educação Ambiental (EA) no Brasil não dispõe de metodologias de ação que estimulem os indivíduos a tornarem-se cidadãos conscientes frentes aos problemas ambientais. O conceito de EA resume-se em enfocar temas relacionados à natureza, 
assumindo um caráter naturalista, distanciando-se do realista, esse que visa um individuo pensante que busca o desenvolvimento sustentável.

Desde os últimos 20 anos a EA ganha destaque como objeto de estudo da ciência. $\mathrm{O}$ Ministério da Educação e Cultura (MEC) preconiza o caráter interdisciplinar da educação ambiental no Parecer $N^{\circ}$ 226/87, de 11 de março de 1987. Em 28 de abril de 1999 o Governo Federal sancionou a Lei $\mathrm{N}^{\circ}$ 9795, que determinou a Política Nacional de EA. Os problemas ambientais mesmo com a implantação dessas leis são debatidos de forma superficial nas instituições de ensino o que impede que a EA seja vista como prática efetiva.

Um programa de EA para ser eficaz deve promover o desenvolvimento de conhecimentos e habilidade necessária para que a comunidade escolar seja capaz de desenvolver atitudes que modifique os comportamentos dos indivíduos compreendidos no processo educacional. Faz-se necessário para isso um Projeto Político Pedagógico (PPP) da instituição de ensino voltado para contemplaçãoda EA com o objetivo de propiciar um desenvolvimento dessa vertente.

Diante disso a função da escola não é simplesmente incentivar em locais públicos e na escola a coleta seletiva de resíduos para serem reciclados, é trabalhar a conscientização para uma sociedade menos consumista e mais consciente, para que assim o indivíduo assuma uma mudança de valores, contribuindo para um projeto de sociedade não excludente e igualitária.

O presente trabalho objetiva demonstrar o uso dos Objetos Virtuais de Aprendizagem (OVA) como ferramenta auxiliadora no processo de ensino aprendizagem com ênfase em Química Ambiental, contribuindo para que os discentes possam exercer a cidadania com responsabilidade, integridade e respeito, articulando, integrando e sistematizando o conhecimento científico no enfrentamento dos problemas ambientais.

\section{REFERENCIAL TEÓRICO}

$\mathrm{Na}$ atualidade os professores estão desenvolvendo a EA em suas práticas pedagógicas apenas reproduzindo a sua formação acadêmica antiga, ao invés de trabalharem a questão ambiental em sala de aula a partir dos conteúdos curriculares. O que não leva o aluno a tornarse sensível frente aos problemas ambientais, descomprometido quanto a sua participação social para um meio ambiente sustentável e não os estimula a encararem o meio ambiente onde estão inseridos como parte integrante de suas vidas. Elucidam que: 
A educação ambiental, é uma atividade meio que não pode ser percebida como mero desenvolvimento de "brincadeiras" com crianças e promoção de eventos em datas comemorativas ao meio ambiente. Na verdade, as chamadas brincadeiras e os eventos são parte de um processo de construção de conhecimento que tem o objetivo de levar a uma mudança de atitude (MEIRELLES; SANTOS, 2005, p.34).

No território brasileiro, assim como em outros lugares do mundo é grave a situação socioambiental. Diante disso a EA deve ser implementada na geração atual com o intuito de formar atitudes de emergência frente aos problemas ambientais. Guimarães (2015, p.32) destaca que o meio ambiente não deve ser compreendido pela metade, e que só através da interdisciplinaridade os indivíduos poderão criar maneiras de estarem em equilíbrio como o mesmo. Assim a EA necessita de aspiração para um meio ambiente sustentável e para a construção de um novo paradigma, a participação efetiva de seus atores, alunos e professores. A EA:

[...] tem um importante papel de fomentar a percepção da necessária integração do ser humano com o meio ambiente. Uma relação harmoniosa, consciente do equilíbrio dinâmico na natureza, que possibilite, por meio de novos conhecimentos, valores e atitudes, a inserção do educando e do educador como cidadãos no processo de transformação do atual quadro socioambiental do nosso planeta (GUIMARÃES, 2015, p.34).

As Tecnologias da Informação e Comunicação (TIC) podem servir de apoio para professores e alunos no processo de ensino aprendizagem. Segundo Miranda (2007, p. 43) “[...] refere-se à conjugação da tecnologia computacional ou informática com a tecnologia das telecomunicações e tem na Internet e mais particularmente na WorlWide Web (WWW) a sua mais forte expressão."A utilização das tecnologias no contexto educacional pode trazer melhorias consideráveis no processo ensino-aprendizagem de Química, ampliando o potencial intelectual do discente, facultando um meio diferente de aprender através de outros recursos, além do tradicional com livros.

Para que as TICs possam trazer alterações no processo educativo, no entanto, elas precisam ser compreendidas e incorporadas pedagogicamente. Isso significa que é preciso respeitar as especificidades do ensino e da própria tecnologia para poder garantir que seu uso, realmente, faça diferença (RAIÇA, 2008, p. 46).

Uma das tecnologiasaliada a esse processo de mudanças atitudinais frente aos problemas ambientais estão os objetos virtuais de aprendizagem que possibilitam a capacidade de simular e animar fenômenos que ocorrem na natureza, além de constitui-se 
como uma ferramenta interativa que favorece uma melhoria na aprendizagem, podendo também ser reutilizado em diversos ambientes. Os OVAs têm como característica a vantagem de possibilitar ao discente fazer varias tentativas, tendo a oportunidade de recomeçar, questionar e com isso construir hipóteses e estratégias sobre o tema abordado, além de obter feedback do computador como auxilio na correção de atividades. Sendo assim diz que:

\begin{abstract}
Um objeto virtual de aprendizagem é um recurso digital reutilizável que auxilia na aprendizagem de algum conceito e, ao mesmo tempo, estimula o desenvolvimento de capacidades pessoais, como por exemplo, imaginação e criatividade. Dessa forma, um objeto virtual de aprendizagem pode tanto contemplar um único conceito quanto englobar todo o corpo de uma teoria. Pode ainda compor um percurso didático, envolvendo um conjunto de atividades, focalizando apenas determinado aspecto do conteúdo envolvido, ou formando, com exclusividade, a metodologia adotada para determinado trabalho (SPINELLI, 2007, p. 7).
\end{abstract}

$\mathrm{Na}$ internet encontram-se disponíveis inúmeros repositórios de objetos virtuais de aprendizagem, vários com conteúdos livrespodendo ser acessados e utilizados gratuitamente, e outros, que não estão disponíveis para o acesso, sendo necessária a permissão para a utilização. O Banco Internacional de Objetos Educacionais (BIOE) é um repositório aberto que pode ser acessado gratuitamente pelo link http://objetoseducacionais2.mec.gov.br/, criado pelo Ministério da Educaçãoem parceria com Ministério da Ciência e Tecnologia (MCT), Rede Latino-americanade Portais Educacionais (RELPE), Organização dos Estados Iberoamericanos (OEI) e algumas Universidades Brasileiras.

O BIOE possui 19.842 objetos publicados, 174 sendo avaliados ou aguardando autorização dos autores para a publicação, apresentando objetos educacionais que se adequam a realidade educacional, estes dispostos em diferente categorias, tais como: Animação/Simulação, Áudio, Experimento Prático, Hipertexto, Imagem,Mapa, software Educacional e Vídeo. No BIOE os objetos contemplam os conteúdos previstos na legislação educacional na educação infantil, ensino fundamental, ensino médio, educação profissional, educação superior e modalidades de ensino (Educação de Jovens e Adultos e Educação Escolar Indígena).

\title{
METODOLOGIA
}


O presente trabalho foi desenvolvido com intuito de apresentar a 41 discentes do $9^{\circ}$ ano fundamental da Escola Estadual de Ensino Fundamental e Médio Estevam Marinho,objetos virtuais de aprendizagem disponibilizados no repositório banco internacional de objetos educacionais, que enfoquem o ensino de Química ambiental. Segundo os PCN:

[...] a principal função do trabalho com o tema Meio Ambiente é contribuir para a formação de cidadãos conscientes, aptos para decidirem e atuarem na realidade socioambiental de um modo comprometido com a vida, com o bem estar de cada um e da sociedade local e global. Para isso é necessário que, mais informações e conceitos, a escola se proponha a trabalhar com atitudes, com formação de valores, com o ensino e a aprendizagem de habilidades e procedimento (BRASIL, 2001, p.29).

O processo metodológico ocorreu em etapas: em primeiro momento fez-se uma pesquisa bibliográfica a fim de selecionar o que já havia na literatura sobre essa temática, bem como reconhecer os principais autores que abordam esse tema, buscou-se trabalhos que versassem diretamente sobre os PCN’s de Química e demais artigos, livros, sites, periódicos que abordama área de Química ambiental. O intuito deste procedimento foi o de poder detectar o nível de concordância entre a orientação oficial para o ensino de Química e os avanços teórico-metodológicos ao uso das Tecnologias da Informação e Comunicação em especial os OVAs. Destacando que:

A pesquisa bibliográfica é feita a partir do levantamento de referências teóricas já analisadas, e publicadas por meios escritos e eletrônicos, como livros, artigos científicos, páginas de web sites. Qualquer trabalho científico inicia-se com uma pesquisa bibliográfica, que permite ao pesquisador conhecer o que já se estudou sobre o assunto (FONSECA, 2002, p. 32).

Em seguida realizou-se pesquisano repositório BIOE com o objetivo de coletar a quantidade de objetos educacionais oferecidos por este repositório para o ensino de Química ambiental para o $9^{\circ}$ ano do ensino fundamental. Os resultados coletados foram dispostos em forma de tabelas. Classifica-se também comouma pesquisa quantitativa. Destacando Fonseca (2002, p. 20): “A pesquisa quantitativa se centra na objetividade. Influenciada pelo positivismo, considera que a realidade só pode ser compreendida com base na análise de dados brutos, recolhidos com o auxílio de instrumentos padronizados e neutros." 
Para realizar uma sondagem sobre o conhecimento do tema por parte dos discentes, aplicou-se uma entrevista semiestruturada, com os alunos dos $9^{\circ}$ ano fundamental da Escola Estadual de Ensino Fundamental e Médio Estevam Marinho, localizada no distrito de São Gonçalo na cidade de Sousa-PB, objetivando propiciar uma aprendizagem significativa, informar e conscientizar sobre a preservação dos recursos ambientais, adotando como metodologia a utilização do OVA. Assim sendo, caracteriza-se como uma pesquisa-ação, pois é um tipo de investigação social que constatou um problema e em seguida desenvolveu-se uma ação para a resolução deste. Salienta que:

A pesquisa-ação pressupõe uma participação planejada do pesquisador na situação problemática a ser investigada. $\mathrm{O}$ processo de pesquisa recorre a uma metodologia sistemática, no sentido de transformar as realidades observadas, a partir da sua compreensão, conhecimento e compromisso para a ação dos elementos envolvidos na pesquisa (FONSECA, 2002, p.35).

Após das aulas teóricas os discentes juntamente com o professor utilizaram os OVAs, os quais permitiram a simulação do exposto na teoria, reconhecendo a química presente nesses processos e como também as principais consequências geradas pela não preservação dos recursos ambientais. Foram aplicados questionários com o propósito de avaliar a aquisição dos conhecimentos frente a essa nova metodologia que versa a educação ambiental.

Caracteriza-se também como descritiva, pois descreve as características de determinado grupo de pessoas, utilizando técnicas como coleta de dados, tais como a observação e o questionário. A pesquisa descritiva:

Observa, registra, analisa e ordena dados, sem manipulá-los, isto é, sem interferência do pesquisador. Procura descobrir a frequência com que um fato ocorre, sua natureza, suas características, causas, relações com outros fatos. Assim, para coletar tais dados, utiliza-se de técnicas específicas, dentre as quais se destacam a entrevista, o formulário, o questionário, o teste e a observação (PRODANOV; FREITAS,2013,p.52)

\section{RESULTADOS E DISCUSÕES}

O BIOE foi acessado pelo link http://objetoseducacionais2.mec.gov.br/. Em seguida clicou-se em ensino fundamental. Este se encontra subdividido em séries finais com 3440 
objetos de aprendizagens disponíveis e séries iniciais com 1628 objetos, totalizando assim 5068 objetos de aprendizagem para este nível de ensino como mostra a figura 1, podendo também ser acessado pelo link http://objetoseducacionais2.mec.gov.br/handle/mec/26.

Figura1- Subdivisão do BIOE para o Ensino Fundamental

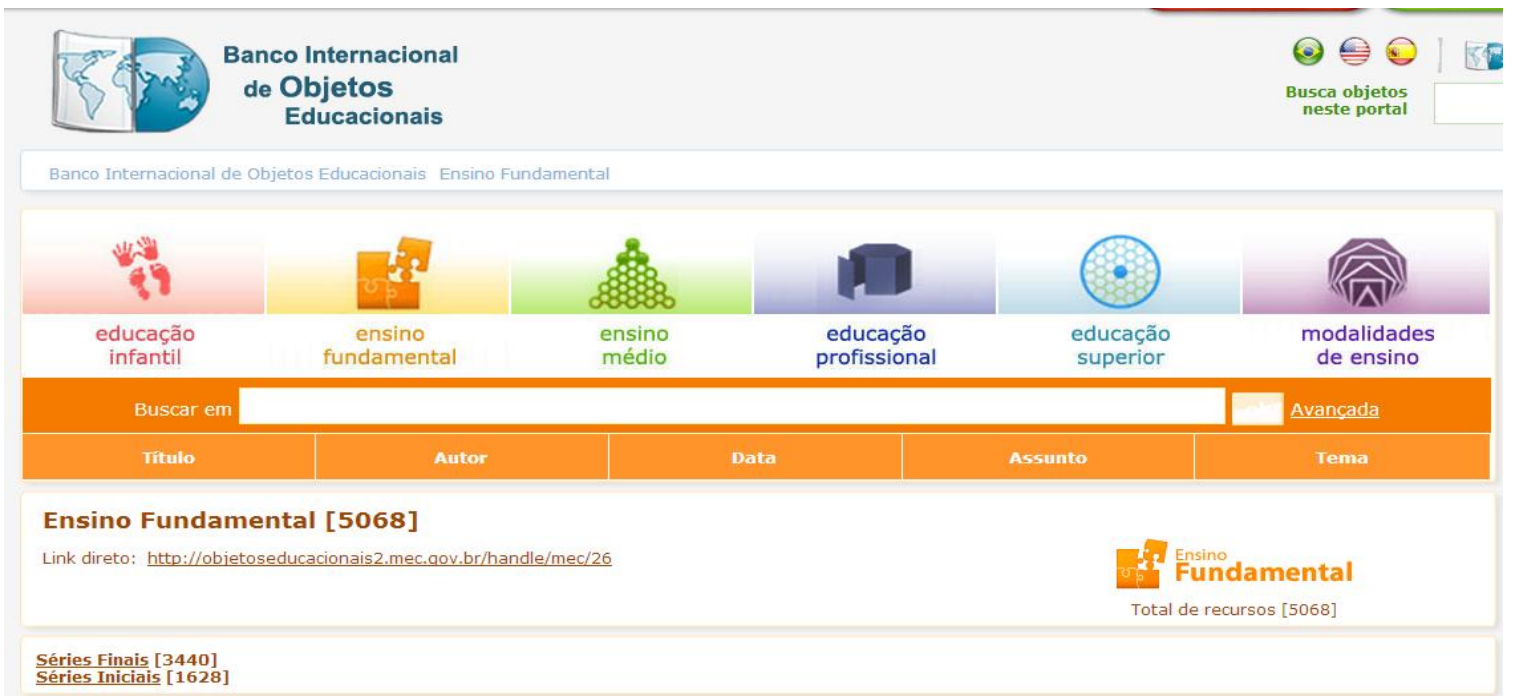

Fonte: BIOE

Os OVAs para o ensino fundamental nas séries finais esta subdivido em: Artes [49] , Ciências Naturais [478], Educação Física [42], Geografia [126] História [85] , Língua Estrangeira [462] ,Língua Portuguesa [237] , Matemática [867] , Meio Ambiente [865] ,Orientação Sexual [8], Pluralidade Cultural [177] , Saúde [44]. Com enfoque no tema meio ambiente o BIOE no ensino fundamental nas séries finais disponibiliza 865 objetos de aprendizagem. Estes por sua vez são subdivididos nas categorias Animações/Simulações com 85 objetos, Áudios 38, Experimentos Práticos 6, Hipertextos 2, Imagens 471, Mapas 2, Softwares Educacionais 14 e Vídeos 247 respectivamente.

Dos 85 simuladores para o ensino fundamental disponíveis, tratam o tema meio ambiente 18, dos quais foram selecionados 2: Mudanças Ambientais Globais e Mudanças Ambientais Globais: impactos no Brasil e no mudo para serem utilizados nos $9^{\circ}$ anos A e B do ensino fundamental.

Antes da aplicação dos OVAs os discentes responderam um questionario com o objetivo de diagnosticar o nivel de conhecimento sobre os temas meio ambiente, OVAs e BIOE. 
Quando questionados sobre o que entendiam sobre o tema meio ambiente os discentes demostraram ter conhecimento e entendimento sobre o conceito. Destacando que meio ambiente é um conjunto de elementos que nos cercam, como elucida o aluno 7 no quadro 2.

Quadro 2- O que você entende por meio ambiente?

\begin{tabular}{|l|l|l|}
\hline $\begin{array}{l}\text { Aluno4 } \\
\text { "O meio ambiente é a casa do } \\
\text { ser humano." }\end{array}$ & $\begin{array}{l}\text { Aluno 7 } \\
\text { "O meio ambiente são as } \\
\text { paisagens, os animais, os rios, } \\
\text { as plantas, tudo que esta ao } \\
\text { nosso redor." }\end{array}$ & $\begin{array}{l}\text { Aluno 11 } \\
\text { "É o espaço onde vivemos. Por } \\
\text { este motivo devemos preserva- } \\
\text { lo." }\end{array}$ \\
\hline $\begin{array}{l}\text { Aluno 19 } \\
\text { "Entendo que é o lugar onde } \\
\text { vivemos e devemos ter o devido } \\
\text { cuidado com a natureza, pois } \\
\text { precisamos dela para } \\
\text { sobrevivemos." }\end{array}$ & $\begin{array}{l}\text { "O meio ambiente faz parte de } \\
\text { nossa vida nossa saúde } \\
\text { depende da pureza do ar." }\end{array}$ & $\begin{array}{l}\text { Aluno 31 } \\
\text { nossa família, onde estamos, } \\
\text { também é a casa dos animais e } \\
\text { plantas." }\end{array}$ \\
\hline
\end{tabular}

\section{Fonte: Proprio Autor}

Segundo os discentes os problemas ambientais são mudanças na paisagem, que modificam e prejudicam a vida do ser humano como mostra o quadro 3. Destacam a importância do trabalho de consciência ambiental para que assim o homem modifique a maneira de agir frente à natureza. Guimarães destaca $(2015$, p.16) que "incorporar a dimensão ambiental na educação, para além de um conteúdo, é uma postura, na qual se ensina e se aprende dando testemunho."

Quadro 3 - No seu entender o que não problemas ambientais?

\begin{tabular}{|c|c|c|}
\hline $\begin{array}{l}\text { Aluno } 3 \\
\text { "Problemas ambientais são o } \\
\text { desmatamento, as queimadas } \\
\text { das brocas e a poluição dos rios. }\end{array}$ & $\begin{array}{l}\text { Aluno } 5 \\
\text { "São problemas gerados pelos } \\
\text { seres humanos que destroem a } \\
\text { natureza." }\end{array}$ & $\begin{array}{l}\text { Aluno } 10 \\
\text { "São o desmatamento das } \\
\text { florestas." }\end{array}$ \\
\hline $\begin{array}{l}\text { Aluno } 16 \\
\text { "Um problema ambiental é a } \\
\text { poluição, que dificulta a nossa } \\
\text { respiração e causa doenças." }\end{array}$ & $\begin{array}{l}\text { Aluno } 17 \\
\text { "São aqueles que prejudicam a } \\
\text { vida do ser humano." }\end{array}$ & $\begin{array}{l}\text { Aluno } 22 \\
\text { "São problemas que tem solução. } \\
\text { Só o ser humano é capaz de } \\
\text { resolver os problemas } \\
\text { ambientais." }\end{array}$ \\
\hline
\end{tabular}

Fonte: Proprio Autor

Como mostra a figura 2, na opinião dos 41 discentes o principal responsável pelos problemas ambientais são os seres humanos como afirmam um percentual de $88 \%$, o segundo responsável é a indústria com $12 \%$. Segundo os PCNs a EA deve estar presente em todas as disciplinas regulares, não se restringindo a biologia e geografia. Neste âmbito a química teve 
tratar não somente de conteúdos meramente teóricos, deve disponibilizar ao individuo uma educação voltada para a consciência ambiental.

Figura 2 - Opinião sobre a responsabilidade pelos problemas ambientais

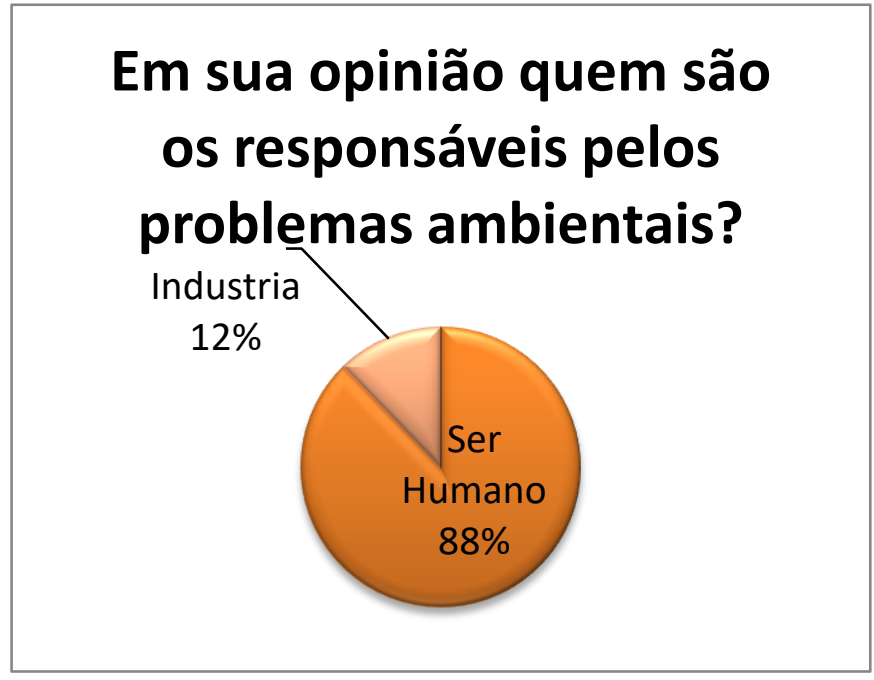

Fonte: Proprio Autor

Dos discentes como destaca a figura3, um percentual de $93 \%$ respoderam que não sabiam o que é um OVA, apenas $7 \%$ elucidaram que já tinham conhecimento do que era um OVA. Tais dados demonstram que apesar de vive-se na era tecnologica os discentes ainda possuem pouco conhecimento sobre os recusos digitais que podem servir de suporte para o ensino de química.

Figura 3- Conhecimento sobre objeto virtual de aprendizagem

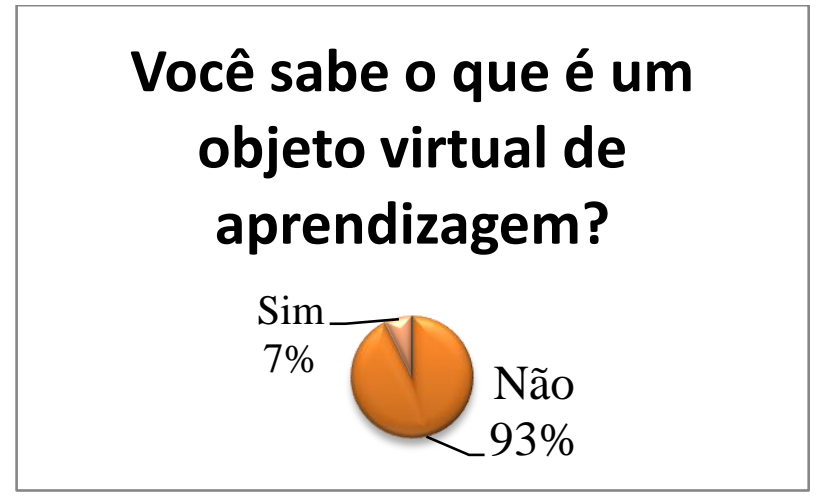

Fonte:Proprio Autor

Todos os discentes não tinham conhecimento do que é o Banco Internacional de Objetos Educacionais (BIOE). Destacaram a não utilização das tecnologias nas aulas da maioria das disciplinas. Dando continuidade às atividades os discentes participaram de uma 
aula expositiva no laboratório de Informática da Universidade Federal de Campina Grande campus de Cajazeiras sobre o que é um OVA, BIOE e como o mesmo pode ser utilizado.

Em seguida os mesmos visualizaram os simuladores: Mudanças Ambientais Globais Abertura;Mudanças Ambientais Globais - Impacto das Mudanças Climáticas no Brasil. Dando continuidade a atividade aplicou-se um questionário de perguntas objetivas e subjetivas com a finalidade de verificar a aplicabilidade desta metodologia utilizando dos OVAs.

Quando questionados sobre quais as consequências das mudanças climáticas segundo o Painel Intergovernamental sobre Mudanças Climáticas (IPCC) os discentes destacaram a elevação do nível do mar como uma das principais consequências, acrescentado que os ecossistemas costeiros e ribeirinhos irão ser alterados drasticamente. Também uma das consequências seria a agricultura e a geração de hidroeletricidade que poderiam ser alteradas devido a mudança de distribuição das chuvas e/ou períodos de longa estiagem. Como destaca o discente U: "Com o aumento da temperatura da terra o homem será o maior prejudicado. $\mathrm{O}$ nível das águas dos mares irá subir e os homens que morampertodali irão ter que irem para outro lugar."

No segundo questionamento os alunos foram provocados a pensar quais seriam as consequências do aumento do aquecimento global no plantio de café, como destaca o quadro 4. Atualmente o café é um dos produtos mais importantes para a indústria brasileira, sendo o Brasil o maior produtor e o segundo maior consumidor mundial. As respostam destacam a importância de nas escolas trabalharem a EA como ênfase nos impactos causados pelo aumento da temperatura do planeta, impactos esses que afetam diretamente a vida do ser humano como elucida o aluno 17. Destacando Barros (2009, p.5): "[...] o trabalho desenvolvido com educação ambiental nas escolas deve ser visto para além do cumprimento de um dispositivo legal. Deve ser visto pelo seu valor como componente essencial para formação de nossos alunos." 
Quadro 4 - Consequências das mudanças climáticas no plantio do café.

\begin{tabular}{|l|l|l|}
\hline $\begin{array}{l}\text { Aluno 6 } \\
\text { "O plantio do café }\end{array}$ & $\begin{array}{l}\text { Aluno 17 } \\
\text { "Migração de São Paulo e e } \\
\text { migraria de São Paulo e } \\
\text { de Minas Gerais para Gerais para a Argentina. } \\
\text { outra localidade." }\end{array}$ & $\begin{array}{l}\text { M O Brasil deixaria de ser o maior } \\
\text { produtor de café, o aumento na }\end{array}$ \\
& $\begin{array}{l}\text { Oesemprego de milhões de de de } \\
\text { pessoas, pois o Brasil é o maior } \\
\text { produto de café” }\end{array}$ & $\begin{array}{l}\text { temperatura da terra acabaria } \\
\text { com plantio. A Argentina seria o } \\
\text { melhor lugar de fazer o plantio } \\
\text { do café." }\end{array}$ \\
\hline
\end{tabular}

Fonte: Proprio Autor

No questionamento seguinte os discentes responderam qual seria a quantidade de emissão de Dióxido de Carbono $\left(\mathrm{CO}_{2}\right)$ em 2100 se o homem continuar a poluir o meio ambiente. $\mathrm{O} \mathrm{CO}_{2}$ conhecido como gás carbônico é um óxido presente na atmosfera terrestre e em excesso é um dos causadores do efeito estufa.

A natureza através do processo da fotossíntese pode solucionar esse problema, por meio da remoção do gás da atmosfera, porém a quantidade de gases é cada vez maior o que impede que a fotossíntese remova todo o $\mathrm{CO}_{2}$ do ar. Até 2100 a emissão de $\mathrm{CO}_{2}$ na atmosfera segundo os 41 alunos será de 917 ppp (partes por milhão), indicando que existem em um milhão de partes do ar 917 partes de $\mathrm{CO}_{2}$.

Quanto ao que indica a projeção da temperatura até o final do século XXI em todo o continente, um percentual de $88 \%$ responderam um aumento da temperatura média da terra para todo o continente devido a grande quantidade de gases na atmosfera, os outros $12 \%$ não souberam responder.

Os OVAs utilizados facilitaram a aprendizagem segundo um percentual de $92 \%$, o aluno $\mathrm{Z}$ destaca que: "Posso ver o que antes o professor apenas falava, consegui compreende que com pequenas atitude o mundo fica melhor.", o aluno $\mathrm{M}$ elucidou "O objeto virtual de aprendizagem facilitou o entendimento do conteúdo, foi interessante poder ver o quanto a poluição atmosférica atingi diretamente a vida do ser humano.”

Esses relatos demostram que as tecnologias são uma forte aliada ao conhecimento, possibilitam ao professor enriquecer sua aula e ao discente desfrutar de aulas dinâmicas. Apenas 5\% responderam que a visualização dos OVAs não facilitou a aprendizagem, justificando que "Não consegui compreender, achei difícil utilizar o simulador. Nunca tinha usado um simular acho que foi por isso." 3\% responderam que facilitou um pouco, não apresentando justificativa. 


\section{CONSIDERAÇÕES FINAIS}

O novo mundo que anseia-se, para que aconteçam transformações sociais requer o engajamento coletivo de professores e alunos. Nas últimas décadas as discussões sobre os problemas ambientais, tomaram uma postura critica frente ao modo como o ser humano lida com o meio em que vive. Diante disso a EA deve estimular a formação de cidadãos para valores e ações que modifiquem o meio em que vivem, a escola é o espaço, propício contribuído para um processo de educação permanente.

A EA nos dias atuais deve ampliar a consciência individual para uma consciência conjunta. Nesta perspectiva os OVAs são um forte aliado ao processo educativo, pois levam a compreensão e permitem que os discentes entendam determinados conceitos. Vale ressaltar que no BIOE para Química no ensino fundamental existem 85 simuladores, e 18 simuladores que tratam o tema meio ambiente. Destacando que a utilização dos OVAs nas aulas de química deve ter como base um paradigma construtivista onde o aluno aprende e com isso torne-se critico frente ao conteúdo, sendo assim um agente ativo e não passivo do conhecimento.

A presente pesquisa contribui para apresentar os objetos virtuais de aprendizagem disponíveis no BIOE aosdiscentes da referida escola e para que outros discentes tomem conhecimento da existência e assim possam também utiliza-los como auxilio nas aulas de química com enfoque no tema meio ambiente, e apresenta um relato de uma aula de química que trabalhou a consciência ambiental com a utilização de OVAs.

\section{REFERÊNCIAS BIBLIOGRAFICAS}

BARROS, Daniela Melaré Vieira; ANTONIO JÚNIOR, Wagner. O Uso de Objetos de Aprendizagem Virtuais na Educação Básica: Subsídios para Inovação na Escola

Pública. s/d. Disponível em: <http://aveb.univap.br/opencms/opencms/sites/ve2007neo/ptBR/imagens/27-06-07/Cognitivas/trabalho_122_wagner_a_anais.pdf >. Acesso em 14.03.2017.

BRASIL. Parâmetros Curriculares Nacionais: meio ambiente e saúde. Ministério da Educação. Secretaria da Educação Fundamental. 3 ed. Brasília, 2001.

FONSECA, J. J. S. Metodologia da pesquisa científica. Fortaleza: UEC, 2002. Apostila. 
GUIMARÃES, Mauro. A dimensão ambiental na educação. $12^{\circ}$ ed. Campinas, SP: Papirus, 2015.

Lei n. 9795 - 27 de abril de 1999. Dispõe sobre a educação ambiental. Política Nacional daEducação Ambiental.

MEIRELLES, Maria de Sousa; SANTOS, Marly Terezinha. Educação Ambiental uma Construção Participativa. $2^{a}$ ed. São Paulo, 2005.

MIRANDA, Guilhermina Lobato. Limites e possibilidades das TIC na educação. Sisifo/revista de ciências da educação. No 3. Maio/ago 2007.

PRODANOV, Cleber Cristiano; FREITAS, Ernani Cesar de. Metodologia do trabalho científico: métodos e técnicas da pesquisa e do trabalho acadêmico. 2 ed. Novo Hamburgo: Feevale, 2013.

RAIÇA, Darcy. Tecnologias para a Educação Inclusiva. 1ed. São Paulo: Avercamp, 2008.

SPINELLI, Walter. Os Objetos Virtuais de Aprendizagem: ação, criação e conhecimento. s/d. Disponível

em: <http://www.lapef.fe.usp.br/rived/textoscomplementares/textoImodulo5.pdf >. Acesso em 09.03.2017. 